\title{
AS ESCOLAS MILITARES DOS ESTADOS UNIDOS E A PENTAGONIZAÇÃO DAS FORÇAS ARMADAS DA AMÉRICA LATINA
}

Dr. Enrique Serra Padrós

(Departamento de História e PPG-História/UFRGS)

\begin{abstract}
Resumo: O presente artigo apresenta a discussão sobre o papel e o protagonismo dos Estados Unidos da América no processo histórico de surgimento e de consolidação das Ditaduras de Segurança Nacional do Cone Sul latino-americano a partir da análise dos seus interesses concretos na região (econômicos, geopolíticos e militares) e da sua percepção quanto ao maior envolvimento da região no contexto e na dinâmica da Guerra Fria.
\end{abstract}

Palavras-chave: Pentagonização, Relações militares EUA-América Latina, contrainsurgência.

\begin{abstract}
This paper aims to analyse the United States of America role and protagonism in the historical process of emergence and consolidation of the Latin American South Cone civil military dictatorships based on the National Security Doctrine. This discussion comes from the analyses of United States interests in the region (economic, geopolitic and military) and from its perception concerning to a greater involvement of the region towards the context and the dynamics of the Cold War.
\end{abstract}

Key-words: Pentagonization- School of Americas - United States of America-Latin American military relations - counterinsurgency

\section{INTRODUÇÃO}

Nos anos 60, as questões concernentes à dinâmica política e econômica da América Latina passaram a ter maior visibilidade, particularmente, em função da Revolução Cubana e dos seus desdobramentos. Entretanto, desde os anos 50, a pressão dos Estados Unidos (EUA) sobre a região vinha se intensificando. Considerando a influência e o impacto que a superpotência, historicamente, projetou sobre o subcontinente, é importante apontar quais foram, no contexto do imediato pós-Segunda Guerra, as diretrizes norteadoras da política externa norte-americana em escala planetária: a contenção da expansão da URSS e do comunismo; a organização da economia capitalista em volta da sua liderança e interesses; a abertura dos impérios coloniais e das metrópoles européias ocidentais aos seus investimentos e comércio; o combate e a contenção da onda revolucionária anticapitalista no Extremo Oriente e, depois, na América Latina e na África. 
No continente americano, as preocupações concretas dos EUA colocaram ênfase no anticomunismo, ${ }^{1}$ na segurança interna e externa, no enquadramento econômico da região e na necessária imposição de uma estabilidade social e política, confiável para os investimentos internacionais. Tal perspectiva incidiu em um cenário de deterioração das condições da maioria da população, onde a ordem social e política estiveram marcadas pelo esgotamento do modelo econômico de industrialização persistente desde o final da grande guerra. Os acontecimentos que envolveram a Revolução Cubana aceleraram a mudança qualitativa do perfil intervencionista estadunidense (marcante, nos anos 50, nos trágicos desenlaces no Brasil de Vargas, na Argentina de Perón e na Guatemala de Arbenz). O medo da "cubanização" da América Latina levou ao co-patrocínio do golpe de Estado de 1964 no Brasil e à promoção da invasão da República Dominicana em 1965, dando início a um novo tipo de relação com a região, o da contra-insurgência.

\section{PENTAGONIZAÇÃO}

Em essência, a "pentagonização" da América Latina foi a expressão da ampliação gradual de uma complexa rede de relações, subordinadas ao poder norteamericano, que compreendeu: intercâmbio de informação, fornecimento de equipamentos militares e munição, treinamento diverso para fins de segurança interna, instrução para ações encobertas, acesso às escolas militares estadunidenses criadas ou reconvertidas para esses fins, oferta de linhas de financiamento específicas, etc. Dessa rede, participaram setores, protagonistas e instituições que, em cada um dos países do Cone Sul, estavam vinculados às funções de segurança e informação. Portanto, a "pentagonização" apontava para as forças de segurança estatais (corpos policiais, militares) ou para-estatais (paramilitares) e consistia na instrumentalização das mesmas para manutenção do status quo local e proteção dos interesses das corporações norte-americanas e dos seus associados, através dessas redes.

\footnotetext{
1 Entende-se por "anticomunismo" um fenômeno que assume valores bem mais profundos que o de uma simples oposição à ideologia e aos objetivos comunistas. Durante a Guerra Fria, particularmente, no plano internacional, o anticomunismo é o critério inspirador de uma política de alcance planetário, cujos objetivos são simultaneamente: a) a contenção da URSS e dos seus aliados; b) a interferência nos negócios internos de cada um dos países, a fim de prevenir e/ou reprimir os movimentos de inspiração comunista (BOBBIO; MATTEUCCI; PASQUINO, 1986. p. 34-35).
} 
É importante lembrar que, nesse período, os impérios coloniais estavam em franco retrocesso e os EUA, além de confrontar a URSS, na lógica da Guerra Fria, estavam reorganizando o mundo capitalista, através da imposição hegemônica diante da Europa e do Japão - economias competidoras, mas ainda muito ressentidas pelo impacto da guerra. Ou seja, para os EUA, havia um duplo e crucial desafio: conter a expansão do comunismo e reorganizar o sistema capitalista mundial sob a sua hegemonia.

Foi nesse duplo desafio que se destacou o fator militar, elemento que contribuiu, tanto na "contenção" do expansionismo soviético, quanto na defesa e garantia do controle sobre a zona de domínio econômico. O fator militar consolidou-se através do denominado “complexo militar-industrial”, estrutura produtiva resultante do enorme esforço de guerra realizado pelos EUA durante o conflito mundial e que, após o mesmo, não foi reconvertido para tempos de paz, persistindo e se tornando, gradativamente, o principal pólo dinâmico do poder econômico estadunidense. A produção bélica adquiriu dinâmica própria e se tornou o centro nevrálgico do capitalismo dos EUA de pós-guerra e, conseqüentemente, um setor fundamental na reestruturação do capitalismo, em escala planetária.

Dentro dessa perspectiva, a "pentagonização" da América Latina extrapolou o objetivo militar dos interesses dos EUA e se constituiu, também, em meio concreto de ampliação de lucros. Ou seja, além de visar bloquear o avanço do comunismo na região, a "pentagonização" reafirmou o poderio militar-industrial dos EUA, assegurando o fornecimento de matérias-primas a preços baixos, obtendo máxima rentabilidade dos investimentos na região e garantindo a fidelidade dos Estados clientes (e subordinados).

Com o advento da Guerra Fria, os EUA incorporaram, a sua política externa, a tese de que sua segurança estava ameaçada em qualquer parte do mundo onde o comunismo esboçava impor-se. Isto levou à estratégia planetária de contenção do poder soviético via conformação de blocos militares com países aliados (caso específico da OTAN). A superpotência procurou garantir a manutenção da rede militar que subordinava as Forças Armadas dos diversos países americanos, através do TIAR, conformando uma espécie de força de reserva que devia desempenhar funções regionais a serviço da estratégia global daquela. A criação do National War College (Escola Superior de Guerra), em 1946, constituiu o ponto de partida da perspectiva de segurança coletiva com a instalação de centros especiais para treinamento, qualificação e doutrinação de militares latino- 
americanos nos EUA. Igualmente, sob sua inspiração, foram constituídas escolas de formação militar na América Latina (Escola Nacional de Guerra do Paraguai, Escola Superior de Guerra da Colômbia, Escola de Altos Estudos Militares da Bolívia, Academia de Guerra do Chile, Escola Superior de Guerra do Brasil).

Simultaneamente, na zona de ocupação no Canal do Panamá, surgiram a Escola do Caribe, do Exército dos EUA (USARCARIB), em Fort Gulick (1949), e uma escola de treinamento de guerrilha, na selva, em Fort Sherman (1953), com o objetivo específico de estruturar unidades avançadas de aperfeiçoamento profissional para oficiais. A evolução dessa relação com os militares da região possibilitou crescente interferência nos assuntos castrenses internos, a partir da construção de uma rede de instrumentos a ser acionada imediatamente, diante de conjunturas instáveis e que, ao mesmo tempo, podia funcionar em períodos menos tensos, como mecanismo de acompanhamento, de vigilância e/ou de controle sobre os acontecimentos regionais.

A aprovação da "Lei de Segurança Mútua" pelo Congresso norte-americano oportunizou convênios bilaterais (Programa de Ajuda Militar), que funcionaram como correia de transmissão do Pentágono a seus aliados locais, que se beneficiaram com o recebimento de material de guerra (mesmo que, às vezes, obsoleto). Um dos mecanismos mais eficientes dessa correia de transmissão foi o treinamento das Forças Armadas e policiais, iniciativa altamente estratégica, pois foi o suporte para uma série de intercâmbios pontuais, que redundaram, ao longo do tempo, em ações positivas no esforço contrainsurgente e na preservação da região como espaço geopolítico do mundo ocidental. A "pentagonização" das forças de segurança da América Latina procurou estabelecer: a homogeneização doutrinária, a padronização de treinamento militar, a articulação de esforços civis-militares nacionais e regionais, a implementação de sistema de propaganda, a montagem de sistemas de informação e de intercâmbio, a venda de material bélico, o estabelecimento de vínculos pessoais e o relacionamento político, alinhado e dependente das diretrizes da Doutrina de Segurança Nacional (DSN) e dos interesses dos EUA. Em última instância, quanto mais se fomentaram as relações desse tipo com as elites políticas e militares locais, maior foi a possibilidade dos EUA administrarem uma grande capacidade de pressão sobre os respectivos sistemas nacionais. 


\section{CONTRA-INSURGÊNCIA}

O advento da Revolução Cubana alarmou os EUA. Frise-se, porém, que a projeção e a tentativa de enquadramento estadunidense sobre o subcontinente foram anteriores. Ressaltar tal fato é importante, para desvendar o discurso oficial dos EUA quanto ao surgimento de uma ameaça comunista regional, justificadora das ações posteriores - justificadas como de teor defensivo - protagonizadas pela superpotência e seus aliados e sócios locais. Nesse sentido, desde 1958, já existia o Comando Sul dos EUA, cuja principal tarefa era orientar a política militar para a América Latina. Posteriormente, nos anos 60, quando da vitória da guerrilha de Fidel Castro e do medo da disseminação regional da experiência revolucionária cubana, foram implementados os primeiros programas de contra-insurgência e a Escola do Caribe passou a ser conhecida como "Escola das Américas". Segundo Langguth, ao voltar para seus países de origem, muitos dos alunos, ali diplomados, mostravam estar tão imbuídos do espírito de rejeição a qualquer interferência civil, que a escola se tornou conhecida, no continente, como "Escola dos Golpes" (s. d., p. 92). ${ }^{2}$ O fato é que, entre 1961 e 1977, mais de 33 mil militares latinoamericanos passaram pelos seus cursos (COMBLIN, 1978, p. 140).

A Crise dos Mísseis, o golpe de Estado no Brasil e a intervenção na República Dominicana demarcaram um ponto de inflexão que acentuou a mudança de orientação dos EUA. A ênfase na democracia e na liberdade persistiria, porém, cada vez mais, como objeto de retórica do discurso oficial. A DSN, a partir dos anos 60 e início dos 70, reforçou a idéia de que a democracia, como valor universal, deveria ser protegida pela Segurança Nacional, a qualquer custo (inclusive, subordinando-a à segurança hemisférica). Quer dizer, um dos pontos mais relevantes na evolução da DSN foi, precisamente, a orientação de agir contra a liberdade, a Constituição e os direitos dos cidadãos para defender, em última instância, a própria democracia.

Sendo assim, a estratégia contra-insurgente disseminada para enfrentar o grave quadro de deterioração, acelerada na América Latina, baseou-se, fundamentalmente, no reforço e na qualificação das forças de segurança, visando uma dupla finalidade. Por um lado,

\footnotetext{
2 Atualmente é lembrada como "Escola de Assassinos", expressão consagrada pela organização de direitos humanos estadunidense School of the American Watch (SOA Watch). Ver: http://www.soaw.org
} 
a sua reconversão e adaptação para a luta contra o que denominaram de subversão interna ou insurgência. Ou seja, qualificá-las para desempenhar um protagonismo inédito no desencadeamento e gerenciamento de ações relativas à segurança interna aproveitando, até, a experiência acumulada pelo poder colonial francês no Vietnã e na Argélia e universalizada pelos EUA no Sudeste Asiático. Por outro lado, realizar a capacitação de uma elite militar para assumir, a curto prazo, funções políticas estratégicas diante da ameaça de rupturas revolucionárias em determinados cenários; formalmente, este segundo objetivo estava situado, pelo menos ainda no início dos anos 60 , dentro dos limites democráticos e de preocupações relativamente reformistas. Efetivamente, houve um esforço para manter, formalmente, as ações militares dentro de certa legalidade institucional, o que explica a complementaridade das estratégias contra-insurgentes e a resultante da aplicação das medidas propostas no bojo da Aliança para o Progresso. O contexto específico, a evolução dos fatos e o início da administração Kennedy parecem confirmar uma preocupação legalista na atuação das Forças Armadas.

Dentro do espírito da Aliança para o Progresso, os estrategistas estadunidenses orientaram as Forças Armadas locais para que contribuíssem na estabilização regional através da realização de atividades que gerassem simpatias junto à população mais pobre, principalmente obras de infra-estrutura física ou de assistência social. Estava em jogo o que Michael Kryzanek identifica como "conquistar os corações e as mentes dos camponeses" (1987, p. 104). Portanto, junto às atividades, envolvendo a luta contra a "subversão", os EUA patrocinaram programas de ação cívica. Estes visavam, fundamentalmente, recuperar a imagem pouco popular dos militares junto às camadas populares e fomentar maior aproximação entre eles. O manual Operaciones de Contraguerrilla, um dos mais estudados nos cursos ministrados na Escola das Américas, destacava a necessidade das Forças Armadas se aproximarem da população mais carente, mediante iniciativas de ação cívica, principalmente em conjunturas de instabilidade. Assim, recomendava-se a participação militar em programas de utilidade pública, como educação, abertura de estradas, edificação de pontes, construção de escolas e moradias populares, cuidado de parques e de praças, atendimento médico e odontológico em regiões afastadas dos centros urbanos.

Também era sugerido o cuidado com o estudo da realidade local (demandas reprimidas, potencialidades), assim como em relação aos fins desejados, pois se temia que a 
ausência de planejamento pudesse inviabilizar o esforço realizado, impossibilitando a reversão das expectativas criadas com a estratégia da ação cívica. As recomendações para a proposição e implementação de projetos exigiam considerar os interesses da população como forma de garantir seu envolvimento e apoio voluntário. Quanto aos benefícios dessas ações concretas, sugeria-se incluir, também, os "cidadãos de duvidosa lealdade" para que pudessem "beneficiar-se do nível de vida de que gozam cidadãos leais" (CUARTEL GENERAL-DEPARTAMENTO DE EJÉRCITO/USA, 1971, p. 154). Desta forma, estas iniciativas pretendiam retirar, das forças insurgentes, facilidades para a cooptação de novos quadros, tentando minar sua influência nas regiões onde, historicamente, as contradições sociais eram mais explosivas e visíveis.

Todavia, as orientações para o desenvolvimento de atividades dentro do espírito da ação cívica não eram contraditórias com a estratégia contra-insurgente. Até nos manuais de instrução afirmava-se que: a ação cívica “[...] apóia as operações táticas, de inteligência, psicológicas, de controle de população e de recursos, e operações de assessoria e, por sua vez, é apoiada por todas essas operações [...]" e está ligada ao centro de comando contrainsurgente (Idem, p. 151). Ou seja, se os militares conseguissem melhorar sua imagem, junto à população, ganhariam sua confiança e um gradual colaboracionismo ou, melhor ainda, apoio ativo. Certamente, este último objetivo era de capital importância, pois, no mesmo momento em que conquistassem a confiança e a simpatia dessa população, conseguiriam afastá-la da esfera de influência da guerrilha, isolando-a, ainda mais, o que aumentava, sensivelmente, as possibilidades de vitória militar contra-insurgente.

$\mathrm{O}$ fornecimento de treinamento, doutrinação, armamento e suporte logístico às Forças Armadas da América Latina está inserido na perspectiva de envolver os atores locais na defesa de uma área percebida pelo Pentágono como inserida na sua segurança interna. A necessidade de multiplicar o treinamento de quadros policiais e militares levou à criação de novas escolas de instrução militar, como Fort Bragg, também na Zona do Canal, e Fort Benning e Fort Leavenworth, nos EUA. ${ }^{3}$ Outra medida importante foi a concentração de

\footnotetext{
${ }^{3}$ Posteriormente, também foram incorporados como centros de treinamento policial: a Academia Nacional do FBI (Washington), especializada em organização de arquivos policiais; a Academia de Patrulha Fronteiriça (Texas), onde se ensinava a confecção de explosivos; a Universidade de Illinois do Sul. A partir de 1975, o Controle Internacional de Narcóticos também passou a encobrir unidades militares e paramilitares que agiam clandestinamente contra grupos políticos e ministrou cursos de técnicas de detenção, entrevistas e interrogatórios, verificação de documentos, busca de pessoas e de veículos e
} 
unidades especiais, estadunidenses, preparadas para entrar em ação imediata no subcontinente, caso fosse necessário. Desde 1962, Fort Gulik sediou o Grupo IV de unidades especiais "boinas verdes" (Special Action Force for Latin América) - e dois batalhões de mariners (um outro batalhão foi instalado na base de Guantánamo, em Cuba).

Essas unidades destacavam-se pela capacidade de rápida mobilização, podendo intervir em qualquer ponto do continente, diante de ameaças pontuais. Eram treinadas em táticas antiguerrilheiras e recebiam aulas de língua espanhola e portuguesa, o que era muito prático, diante da possibilidade futura de terem que se mover no meio de civis latinoamericanos. Tais unidades eram organizadas em 17 equipes (uma para cada país da região), destinadas a serem rapidamente transportadas diante da solicitação de qualquer governo "amigo". Treinadas em cursos de "Operações Especiais", especializaram-se em ações de atentados, sabotagem, assassinatos, emboscadas, explosões, espionagem, incursões, vigilância e amedrontamento. Segundo Claude Julien, nos anos 60, unidades "boinas verdes" chegaram a intervir em toda a América Latina, com exceção de Cuba, Haiti e México (1969, p. 303).

A Guerra do Vietnã absorveu parte dos quadros treinados para ações na América Latina. Aliás, as experiências adquiridas naquele conflito foram incorporadas, posteriormente, nas operações militares e paramilitares, desenvolvidas junto aos exércitos latino-americanos. A semelhança da metodologia de "guerra suja", aplicada no Sudeste Asiático e o treinamento que as unidades especiais receberam para intervir na América Latina, não foi casualidade. No Vietnã, foi aplicada a mesma lógica, que combinava ações contra alvos militares e contra a população civil (disseminando o medo através do terror). Em realidade, tanto na América Latina quanto no Sudeste Asiático, as unidades especiais, independente da existência de uma declaração formal de guerra, desencadearam operações típicas de "guerra suja": eliminação de guerrilheiros ou de pessoas suspeitas de colaborar com eles, assassinato de cidadãos "esquerdistas", organização de sublevações e sabotagens contra o poder constitucionalmente instituído, práticas de terror, etc. Aliás, a Embaixada Estadunidense de Saigon recebeu inúmeras denúncias de torturas e de assassinatos, cometidos pela polícia local (treinada pelos especialistas dos EUA), sendo que, muitas

métodos de vigilância de portos e fronteiras (extrapolando seu objetivo original e adentrando na repressão política). 
vezes, tais fatos aconteciam diante da presença de agentes desse país (LANGGUTH, s. d., p. 127).

Apesar da derrota militar no Vietnã, os EUA continuaram associando toda manifestação reformista ou antiimperialista, em qualquer parte do planeta, como "agressão comunista" e, conseqüentemente, assunto da sua segurança interna. Mas houve, sim, uma reavaliação sobre o seu envolvimento bélico, em grande escala, fato motivado pela pressão da opinião pública interna diante da morte e mutilação de milhares de soldados naquele conflito. Porém, o revés sofrido não mudou, na sua essência, a política para a América Latina; ao contrário, em 1974, recém golpeadas as democracias chilena e uruguaia e num momento de intensa luta armada, na Argentina, os EUA impuseram, via Junta Interamericana de Defesa e OEA, o denominado Plano LASO (Latin American Security Operation), projeto elaborado pelo Pentágono no início dos anos 60 e que estabelecia que o confronto com a guerrilha implicaria os seguintes passos: a) montagem de infra-estrutura para sustentar as etapas posteriores; b) eliminação dos focos guerrilheiros e suas bases de sustentação (inclusive os denominados braços políticos); c) retenção territorial, a partir da eliminação da guerrilha e da inviabilização do surgimento de novas organizações armadas; d) estabilização, através de políticas de pacificação e reversão de descontentamentos sociais. No final dos anos 70, com o Cone Sul estabilizado pela disseminação das ditaduras de Segurança Nacional, os EUA deslocaram sua atenção para a América Central, onde a Nicarágua, El Salvador e a Guatemala tornavam-se os novos alvos de aplicação das diretrizes citadas (ZUBENKO; TARASÓV, 1984, p. 47).

\section{CAPACITAÇÃO MILITAR}

O modelo de treinamento das unidades "boinas verdes" foi o referencial adotado para a capacitação dos exércitos latino-americanos. A irrupção da "via cubana" não é suficiente para explicar tamanho esforço dos EUA; em realidade, outros fatores também estavam em jogo. O preço da escalada bélica no Vietnã levou os EUA a considerarem, para a realidade latino-americana, a criação de outro tipo de mecanismo de intervenção eficiente nos assuntos internos de cada país. Para a superpotência, tornou-se prioritário evitar a exposição ao desgaste político, humano, militar e econômico de uma invasão e/ou ocupação 
territorial. Um pequeno exemplo está no seguinte dado: em 1967, o custo médio de formação e de treinamento de um soldado latino-americano (percebido, segundo a nova lógica, como integrante de unidades militares "complementares"), era dez vezes inferior ao de um estadunidense (COGGIOLA, 2001, p. 16). Portanto, a inserção das Forças Armadas da América Latina, visando a contenção anticomunista, diminuiu os gastos que a superpotência dispensava as suas tropas, desobrigando-as de ações diretas questionáveis, diante da opinião pública e do direito internacional, e repassava, aos demais países, o maior desgaste, no combate aos focos "subversivos". Os EUA, com a sensível diminuição do custo da manutenção da rede de proteção e de segurança dos seus próprios interesses, combinado com as expectativas comerciais da indústria bélica, beneficiaram-se do lucro gerado por essa engenharia político-militar, emoldurada pelo discurso da segurança. As palavras de Robert McNamara, a esse respeito, são bem eloqüentes:

\begin{abstract}
Os EUA não podem estar em todo lugar simultaneamente. A balança de forças e as necessárias alternativas com o mundo contemporâneo em transformação só podem ser conquistadas com amigos fiéis, bem equipados e prontos para cumprir com a tarefa que lhes cabe. O Programa de Assistência Militar foi projetado para impulsionar e conquistar tais forças e alternativas, já que ajuda a manter forças militares que complementam nossas próprias forças armadas. ${ }^{4}$
\end{abstract}

O treinamento ministrado pelos especialistas dos EUA tornou-se uma oportunidade de ascensão na carreira e de melhoria salarial para os quadros escolhidos. Os oficiais que passavam por tais cursos conseguiam promoções mais rápidas, tinham mais oportunidades de serem chamados para tarefas especiais ou atividades de assessoramento e podiam vir a assumir protagonismos futuros que constituíam expectativas concretas de vantagens pessoais (altos postos de comando, cargos ministeriais, direção de empresas públicas, representação em missões no exterior, etc.). Este mecanismo, indiretamente, consolidava a influência da superpotência sobre a orientação da política de segurança interna dos governos locais.

Preocupação particular mereceu a polícia. Na tradição regional, as Forças Armadas só assumiam tarefas de manutenção da ordem pública e prevenção de delitos quando a ação insurgente transbordava a capacidade das forças policiais. Estas, nos anos 60, passaram a receber a mesma preparação destinada aos militares a partir do

\footnotetext{
4 Declaração de Robert McNamara, Secretário de Defesa dos EUA em defesa do Programa de Assistência Militar para o ano fiscal de 1967 (COGGIOLA, 2001, p.16).
} 
convencimento de que a melhor prevenção era uma polícia eficiente. Dentro da perspectiva da biologização da ameaça comunista, a eficiência policial foi vista como sintoma de uma "medicina preventiva", ou seja, se a polícia falhasse, sempre restaria o recurso da cirurgia maior: a intervenção militar. ${ }^{5}$

O principal centro de instrução das forças policiais foi a Academia Internacional de Polícia (IPA), por onde passaram mais de cinco mil agentes estrangeiros. Por detrás do discurso da profissionalização e da qualificação da ação policial contra-insurgente, houve uma apologia da violência, através da promoção de métodos de tortura. Para Martha Huggins, a qualificação repressiva das forças locais, como meio de fortalecimento da democracia (discurso oficial dos EUA e dos aliados locais), escondeu, paradoxalmente, o contrário, ou seja, que o reforço do autoritarismo ocorreu com o aumento da subordinação à orientação norte-americana, a partir dos critérios de "internacionalização", "centralização", "recrudescimento do autoritarismo" e "degenerescência" (1998, p. 105).

Embora a autora centre sua análise no aparelho policial, sua perspectiva é extensiva às forças militares. Nesse sentido, a "internacionalização" das forças de segurança latino-americanas foi um dos objetivos regionais prioritários dos EUA pois, além de obter influência através da formação prática e do fornecimento de armamento, permitiu-lhe penetrar no sistema de segurança local, mediante relações privilegiadas com oficiais que ocupassem cargos estratégicos, inclusive inserindo quadros da CIA ou do FBI e encobrindo agentes duplos.

A "internacionalização" da segurança dos EUA exigiu a formação de redes de defesa interna nos países aliados/associados que se conectaram, por sua vez, à rede internacional nucleada e "centralizada" pela superpotência. Para tanto, precisava-se da colaboração dos quadros treinados na Escola das Américas e demais centros de instrução e que desempenhavam funções estratégicas de liderança e de chefia em organismos locais de segurança. A "centralização" do sistema de segurança dificultou o contraditório político e instalou uma estrutura verticalizada de controle o que, em síntese, intensificou a militarização da segurança e o "recrudescimento do autoritarismo". Para a superpotência, a "centralização" da rede de segurança deveria evitar sua fragmentação, a divisão em facções competidoras ou o

\footnotetext{
5 Este raciocínio foi apresentado, em 1971, pelo Subsecretário de Estado, Alexis Johnson, diante do Congresso. Idem, p. 50.
} 
funcionamento autônomo dos seus componentes.

Quanto à "degenerescência" do sistema, Huggins refere-se à eventual perda do controle estatal e à autonomização de grupos repressivos. ${ }^{6}$ Um dos motivos dessa manifestação poderia ser o surgimento de conflitos, disputas e contradições internas, inerentes à dinâmica do sistema e à ação dos seus atores. Tal situação poderia gerar um processo de desburocratização que diminuísse o controle sobre os diversos setores repressivos, conferindolhes, conseqüentemente, maior autonomização de atuação (caso dos esquadrões da morte). A situação de "degenerescência" expressa, também, possibilidades de situações de confronto e de espionagem no interior do aparato repressivo, que deviam ser evitadas a todo custo. De qualquer maneira, tais situações foram parte da engrenagem do funcionamento do Terrorismo de Estado. Em realidade, em certas conjunturas, interessou ao Estado desconectar-se de uma violência mais extremada, deslocando-a para grupos paramilitares e parapoliciais que, na prática, também eram por ele orientados, sustentados e dirigidos.

Através da rede de centros de instrução e de missões militares e policiais estabelecidas em diversos países da região, os EUA prepararam forças de segurança regionais para que assim desempenhassem tarefas de vigilância interna. Das atividades desencadeadas, fizeram parte manobras conjuntas, contatos permanentes, treinamento e capacitação profissional, intercâmbio de delegações nas Escolas Superiores Militares, divulgação e estudo da bibliografia produzida por especialistas em luta anti-subversiva, treinamento específico com armamento incorporado pelas forças locais e, principalmente, cursos de formação de quadros, que cumpriam função estratégica, pois seriam, posteriormente, encarregados de retransmitir os ensinamentos adquiridos aos militares e policiais dos respectivos países.

\footnotetext{
${ }^{6}$ A ditadura argentina foi o maior exemplo de autonomia operacional de algumas unidades repressivas. As mesmas deviam respeitar os espaços delimitados para evitar tensões, disputas e confrontos pela apropriação do "botim". A tendência à autonomização contrariava a orientação de Washington, pois a quebra da unidade da ação repressiva estatal poderia combinar-se com a quebra de hierarquia e diminuir a eficiência no combate contra a "subversão". Fato semelhante ocorreu com a Operação Condor. Após ter participado indiretamente da sua orquestração, os Estados Unidos mostraram desconforto e mal-estar com alguns operativos específicos, como os atentados perpetrados em território europeu, os quais trouxeram desdobramentos diplomáticos desgastantes. Entretanto, o fato de maior repercussão negativa foi o atentado que matou Orlando Letelier (ex-chanceler de Allende) e a cidadã estadunidense Ronny Moffit, em Washington. Segundo documentos desclassificados pelos EUA, o crime foi dirigido por agentes da DINA chilena encobertos por documentação paraguaia (solicitada como "favor urgente" pelo general Pinochet ao general Stroessner) e efetuado em conjunto com dissidentes cubanos vinculados à CIA (BOCCIA PAZ et al., 2002. p. 160-164). Na obra de Stella Calloni Operación Cóndor: los años del lobo (1999), há sérias acusações contra a CIA e seu então diretor, George Bush, por envolvimento no assassinato de Letelier.
} 
O aumento da tensão política na América Latina obrigou a intensificar os programas de assistência econômica e militar. Assim, em 1964, a Agência Internacional de Desenvolvimento (AID) aumentou o número de vagas dos cursos ministrados em Fort Bragg; em 1966, os programas de treinamento policial em contra-insurgência urbana consumiam 38\% do orçamento de assistência econômica para toda a região. Dessas linhas de auxílio, fez parte, entre outras, a consultoria de 23 especialistas policiais, enviados ao Brasil, entre 1963 e 1971, para complementar e atualizar o treinamento de 641 policiais brasileiros que haviam estudado na Academia Policial Internacional, em Washington (SCHOULTZ, 2000, p. 397).

Durante a estadia de Dan Mitrione, o expert em técnicas de interrogatório (“tortura científica”), no Brasil, os especialistas locais ficaram admirados com a facilidade com que o agente do FBI montava academias policiais e laboratórios de criminalística. Os pedidos de apetrechos diversos, solicitados por Mitrione aos programas de ajuda mantidos pelos EUA para qualificar e modernizar o trabalho das unidades repressivas, como câmaras, projetores, telas, material de impressões digitais e artigos fotográficos, sempre eram prontamente atendidos (LANGGUTH, s. d., p. 74).

Diante dos questionamentos formulados por congressistas norte-americanos, de que o custo da ajuda aos sócios e aliados da região era muito alto, o general Robert Wood esclarecia, como a assistência militar ministrada repercutia, beneficamente, sobre a economia e a segurança do próprio país:

Que é então a assistência militar? É um programa com cujos fundos são feitas compras à indústria norte-americana, para as forças dos países estrangeiros que, contando com vontade e material humano, carecem de meios de defesa; é um programa que traz a nosso país entre dez e quinze mil estudantes militares estrangeiros anualmente, expondo-os não somente ao conhecimento militar norte-americano, como também ao modo de vida norte-americano; é um braço da política exterior dos EUA; defende predominantemente nosso interesse nacional (apud COGGIOLA, 2001, p. 16). [Sublinhado meu]

Quer dizer, Wood, pragmaticamente, associava complexo militar-industrial, segurança nacional e ideologia como fatores-chave dos interesses concretos dos EUA na América Latina.

Dos cursos ministrados na Escola das Américas, os mais destacados foram: $1^{\circ}$ ) operações técnicas (comunicações, engenharia e manutenção de armas e veículos); $2^{\circ}$ ) operações de apoio (cursos de polícia militar, logística e sanidade); $3^{\circ}$ ) departamento de 
mando para chefes de alta patente e oficiais do Estado Maior (mesmo modelo de formação dos futuros generais estadunidenses); $4^{\circ}$ ) operações de combate com treinamento em guerra irregular na selva (práticas de emboscada, assaltos), combate à guerrilha urbana e técnicas de investigação criminal sofisticadas.

Em relação ao último curso, adquiriam especial importância, temas de ideologia, ação psicológica, inteligência e contra-espionagem. As aulas práticas, de extrema abrangência, envolviam infinidade de variáveis dentro da luta contra-insurgente: seleção e uso de informantes, métodos de proteção de dirigentes, desativação de aparatos explosivos, treinamento em cordão policial, operações de busca, operações de contraguerrilha, tática militar de desfolhamento, inteligência eletrônica, inteligência, contra-inteligência insurgente, subversão e contra-subversão, espionagem e contra-espionagem, interrogatório de prisioneiros e de suspeitos, treinamento para lidar com comícios, reuniões de massa e tumultos, fotografia para o serviço secreto, controle de recursos, operações psicológicas, batidas e buscas policiais, vigilância, terror e operações secretas, etc.

Manuais específicos para enfrentar o foco insurgente foram distribuídos. Por exemplo, no manual de Operaciones de Contraguerrilla, além das questões militares propriamente ditas, o objetivo essencial de cooptar civis impunha recomendações para estabelecimento de contato com a população, preocupação pertinente diante das pressões morais e psicológicas decorrentes dessa situação. Tratava-se de preparar os comandos quanto aos condicionamentos que podiam sofrer no contato com um fator humano, cuja postura podia variar, desde atitudes receptivas e colaboracionistas até demonstrações de franca hostilidade.

O interrogatório e as formas de obtenção de informação foram um dos aspectos centrais dos cursos de instrução. A necessidade de coleta de informação para medidas preventivas de segurança foi vinculada, apesar de não fazer menção explícita, ao uso da tortura. A realização de tais cursos, tanto em território dos EUA, quanto nos países que acolhiam suas missões (caso do citado Dan Mitrione, por exemplo), foi algo sempre negado pelo governo norte-americano e pelos aliados regionais. O registro feito pelo "boina verde" Donald Duncan, é bem ilustrativo a esse respeito. Duncan relatou que um soldado, após presenciar na aula, a aplicação de diversas técnicas de tortura para arrancar informação, ao perguntar ao instrutor se pretendia que os alunos empregassem esses métodos, ouviu como 
resposta: "Não podemos dizer-lhe isso, Sargento Harrison. As mamãezinhas aqui nos Estados Unidos não aprovariam”. Para dirimir qualquer dúvida a respeito, o instrutor acrescentou: "Além disso, negaremos ter ensinado ou pretendido que se fizesse tal coisa" (LANGGUTH, s. d., p. 215).

Diante de denúncia de tortura, em países da região, com alusões ao treinamento oferecido pelo Pentágono, o governo dos EUA, geralmente, responsabilizou as forças de segurança locais, sugerindo, com esse estratagema, que os excessos cometidos eram de iniciativa das mesmas. Tal postura foi denunciada, por exemplo, pelo ex-oficial do Serviço de Inteligência Naval do Uruguai, Victor Paulo Laborde, que confirmou que os métodos de tortura aplicados aos presos políticos eram elaborados nos EUA, onde eram formados especialistas em tortura. Ele próprio havia sido treinado por oficiais dos Estados Unidos, através de aulas práticas e de manuais militares, que não passavam de textos didáticos norte-americanos, traduzidos e destinados à formação dos especialistas locais (ZUBENKO; TARASÓV, 1984, p. 25).

Um objetivo importante dessa rede de treinamento e capacitação antiinsurgente foi a introjeção, no aluno, de que o rol protagônico, decorrente da sua função militar, dependia das suas atitudes e iniciativas. Assim, a DSN abria uma "nova dimensão da política interna" ao convocar a participação da corporação militar, exigindo-lhe que extrapolasse a simples intervenção, saneadora e transitória, assumindo o protagonismo necessário para "refundar" o Estado. Questionando a ineficiência e a corrupção moral do poder civil (sobretudo dos partidos políticos), em prevenir e extirpar os focos radicais resultantes das mazelas sociais e das políticas econômicas locais existentes, a combinação de programas de contra-insurgência, com a ação cívica militar, serviu para catapultar as Forças Armadas. Sob o disfarce da tecnocracia e da neutralidade da corporação, os cursos de treinamento de oficiais especializados na repressão anti-subversiva foram fundamentados, em termos doutrinários, na defesa dos sentimentos mais profundos da Nação e dos valores da civilização cristã-ocidental. É inegável, portanto, que um dos objetivos primordiais da formação militar, ministrada pelos especialistas estadunidenses aos seus congêneres latino-americanos, visou convencê-los da necessidade de assumir, direta ou indiretamente, as tarefas políticas do país, pois, as Forças Armadas eram o último baluarte para defender a sociedade e os valores cristão-ocidentais da terrível ameaça 
comunista (COMBLIN, 1978, p. 142).

Tanto treinamento e informação, oferecidos através dos diversos cursos e programas, exigiam dos alunos que aplicassem os conhecimentos adquiridos à realidade dos seus respectivos países de origem. Uma das formas práticas mais imediatas era a obrigatoriedade, em muitos dos cursos, de que o aluno, ao concluir seus estudos, elaborasse uma monografia que, de forma concreta, auxiliasse no combate à insurgência. Obrigava-se a esses oficiais-alunos, muitos deles ainda detentores de baixa patente, a propor soluções adequadas para as demandas anti-subversivas dos seus países. Como já foi dito, o governo dos EUA tinha a expectativa de que, num futuro não muito distante, parte deles ocuparia cargos de comando. Efetivamente, esta foi uma das perspectivas mais estratégicas que nortearam a abertura das escolas militares dos EUA para as Forças Armadas latinoamericanas. Nesse sentido, em outubro de 1973, o Pentágono reconhecia, com satisfação, o sucesso dos seus cursos e do investimento feito para enfrentar a ameaça comunista no continente, através da estratégia de dividir custos e responsabilidades com as Forças Armadas locais. Naquele ano, o Pentágono contabilizava 170 alunos, diplomados pela Escola das Américas, desempenhando funções de Chefes de Estado, Ministros, Comandantes em Chefe das Forças Armadas ou diretores dos Serviços de Inteligência (COMBLIN, 1978, p. 141).

O exemplo mais emblemático e explícito de atuação contra-insurgente foi a paradigmática intervenção, no Chile, da Unidade Popular, interferindo contra um governo democraticamente eleito e respeitoso da legalidade constitucional democrática. Na véspera de setembro de 1973, no contexto do golpe contra Allende, os EUA já se haviam definido, abertamente, pela prioridade da segurança, em detrimento da democracia. Tal posição estava implícita, exemplarmente, na lapidar frase de Kissinger: "Não vejo por que temos de ficar parados enquanto um país se torna comunista pela irresponsabilidade de seu povo" (HITCHENS, 2002, p. 13). Tal frase não surpreende, apesar do grave significado antidemocrático, intervencionista e preconceituoso que contém, além de ter-se tornado um dos primeiros registros do modelo de ação preventiva da política exterior norte-americana. O envolvimento explícito dos EUA no golpe que depôs o governo da Unidade Popular é mais grave, ainda, se considerarmos que ele iniciou, antes do próprio pleito eleitoral que deu a vitória à coalizão liderada por Allende; ou seja, a conspiração golpista já estava em 
marcha, anos antes do trágico 11 de setembro chileno (e latino-americano) e, nela, os EUA desempenharam um papel central - particularmente através da CIA. ${ }^{7}$

Apesar do caso chileno ter sido paradigmático, quanto ao intervencionismo dos EUA na América Latina, no contexto da Guerra Fria, deve ressaltar-se o interesses, presentes sobretudo, nos seus diplomatas, nas suas empresas e nos seus agentes, nas situações de deterioração das relações políticas, em outros tantos casos nacionais que levaram aos golpes de Estado, assim como o apoio sistemático às ditaduras de Segurança Nacional resultantes.

\section{REFLEXÕES FINAIS}

Concluindo, a gradual "pentagonização" das Forças Armadas latino-americanas acentuou a sua dependência ao exército estadunidense, não só pelo fornecimento de armamento, peças de reposição e equipamentos adicionais, mas também pela instrução que sua oficialidade recebeu nas academias dos EUA, bem como pelos tratados militares bilaterais e regionais que procuraram uniformizar abastecimentos, manobras, estratégias e pontos de vista sócio-políticos emitidos pelo Pentágono. Em síntese, na América Latina houve, a partir dos anos 50, respeitadas as especificidades nacionais, um processo crescente de interferência, a "pentagonização", cujas tendências gerais foram:

a) a exploração da região segundo as necessidades do complexo militarindustrial;

b) a imposição de diretrizes resultantes da conexão do complexo militarindustrial com a Doutrina de Segurança Nacional;

c) o enfrentamento de todo foco de questionamento na região, tanto à ordem vigente, quanto à ingerência política dos EUA;

d) a fragilidade da soberania dos países da região diante da política externa estadunidense.

\footnotetext{
${ }^{7}$ Com a autoridade de ser um dos maiores especialistas em política externa norte-americana e de utilizar documentação oficial, Noam Chomsky afirma que a ação de desestabilização do Chile e do governo Allende havia começado muito tempo antes: "A primeira manipulação ilegal da Casa Branca do processo eleitoral chileno contra Salvador Allende se deu nas eleições presidenciais de 1964, nas quais a CIA gastou mais de três milhões de dólares em operações políticas secretas - comprando jornalistas e políticos, fomentando calúnias e mentiras sobre o candidato - para impedir o triunfo de Salvador Allende" (CHOMSKY, 1998, p. 221).
} 
Conseqüentemente, tal processo acarretou, no contexto da Guerra Fria, um forte alinhamento de diversos governos regionais, aos EUA, dos quais foi incorporada a Doutrina de Segurança Nacional e os postulados básicos da guerra contra-insurgente; sua aplicação concreta, combinada, resultou em regimes repressivos, marcados por um profundo autoritarismo e uma cultura de medo, que se irradiou pelo conjunto das sociedades da região, deixando seqüelas que persistiram, inclusive, mesmo após o fim do ciclo das ditaduras.

\section{REFERÊNCIAS BIBLIOGRÁFICAS}

BOBBIO, Norberto; MATTEUCCI, Nicola e PASQUINO, Gianfranco. Dicionário de política. Brasília: Editora Universidade de Brasília, 1986.

BOCCIA PAZ, Alfredo et al. En los sótanos de los generales. Los documentos ocultos del operativo Cóndor. Asunción: Expolibro/Servilibro, 2002.

CALLONI, Stella. Operación Cóndor: los años del lobo. Buenos Aires: Peña Lillo y Ediciones Continente, 1999.

CHOMSKY, Noam. Um olhar sobre a América Latina. Rio de Janeiro: Oficina do Autor, 1998.

COGGIOLA, Osvaldo. América do Sul na era das ditaduras militares. São Paulo: Editora Contexto, 2001.

COMBLIN, Padre Josep. A Ideologia da Segurança Nacional. O Poder Militar na América Latina. Rio de Janeiro: Civilização Brasileira, 1978.

CUARTEL GENERAL, DEPARTAMENTO DE EJÉRCITO (USA). Operaciones de contraguerrilla. Buenos Aires: Editorial Rioplatense, 1971.

HITCHENS, Christopher. O julgamento de Kissinger. São Paulo: Boitempo, 2002.

HUGGINS, Martha K. Polícia e política: relações Estados Unidos / América Latina. São Paulo: Cortez Editora, 1998.

JULIEN, Claude. El imperio americano. México: Grijalbo, 1969. 
KRYZANEK, Michael J. Las estrategias políticas de Estados Unidos en América Latina. Buenos Aires: Grupo Editorial Latinoamericano, 1987.

LANGGUTH, A. J. A face oculta do terror. São Paulo: Círculo do Livro, s. d.

SCHOULTZ, Louis. Estados Unidos: poder e submissão. Uma história da política norteamericana em relação à América Latina. Bauru, SP: EDUSC, 2000.

ZUBEnKo, V., TARÁSOV, K. La CIA contra América Latina. Moscú: Editorial Progreso, 1984. 